\title{
Tuberculose canina e sua importância em saúde pública*
}

\author{
Canine tuberculosis and its importance in public health
}

\author{
Jane Megid*, Ana Paula F.R.L. Bracarense ${ }^{* * *}$, Antonio Carlos F. dos Reis***, Domingos José \\ Sturion $^{* \star * \star}$, Lígia M.M.Martin ${ }^{* * * *}$, Sônia R. Pinheiro ${ }^{* \star * * * *}$
}

\begin{abstract}
MEGID, J. et al. Tuberculose canina e sua importância em saúde pública. Rev. Saúde Pública, 28: 309-10, 1994. Relata-se um caso de uma família com diagnóstico de tuberculose, cujo cão também apresentava a enfermidade. Discute-se a importância do rastreamento epidemiológico animal em casos de tuberculose humana.
\end{abstract}

Descritores: Tuberculose, epidemiologia. Doenças do cão. Vigilância epidemiológica.

\section{Introdução}

A tuberculose é uma importante causa de incapacidade e morte em muitos países do mundo (Benelson'2, 1992).

Para o ser humano, os fatores mais importantes no contágio são a infecciosidade da fonte de infecção e a proximidade de contato. Casos com baciloscopia positiva (visualizados pelo esfregaço) são altamente infecciosos, enquanto que aqueles positivos somente em cultura são menos infectantes (Des Prez e Goodwin, citados por Mandell e col. ${ }^{6}, 1985$ ).

Muitas espécies de mamíferos domésticos são sensíveis aos agentes da tuberculose (OPAS ${ }^{7}$, 1989). Os cães se infectam através de exposição maciça e repetida, ao coabitarem com pacientes humanos ou ao consumir repetidas vezes produtos contaminados. Em torno de $75 \%$ dos casos caninos são causados pelo $M$. tuberculosis e somente $25 \%$ são devidos ao $M$. bovis, (OPAS ${ }^{7}, 1989$ ).

A importância do ser humano como fonte de infecção para os cães é um fato bastante conhecido

\footnotetext{
* Trabalho apresentado no XXII Congresso Brasileiro deMedicina Veterinária, Curitiba, PR, 1992.

* Departamento de Higiene Veterinária e Saúde Pública. Faculdade de Medicina Veterinária e Zootecnia - Universidade Estadual Paulista, Botucatu - Botucatu, SP - Brasil

*** Departamento de Medicina Veterinária Preventiva. Universidade Estadual de Londrina - Londrina, PR - Brasil

**** Departamento de Cirurgia Veterinária. Universidade Estadual de Londrina, Londrina, PR - Brasil

***** Prefeitura Municipal de Cambé - Cambé, PR - Brasil

******Departamento de Medicina Veterinária Preventiva e Saúde Animal. Faculdade de Medicina Veterinária. Universidade de São Paulo - São Paulo, SP - Brasil
}

Separatas/Reprints: J. Megid - 18618-000 - Botucatu, SP Brasil

Edição subvencionada pela FAPESP. Processo 94/0500-0
(Steele $^{8}, 1980$ ), assim como, animais de comportamento amigável podem favorecer contatos íntimos e constantes. Apesar disso, a avaliação dos animais familiares não é considerada quando do atendimento de pessoas tuberculosas.

O presente relato tem como objetivo alertar para a importância do rastreamento epidemiológico dos animais contactantes, uma vez que os mesmos são suscetíveis e passam a atuar como fontes de infecção.

\section{Relato do Caso}

Em uma família constituída por 18 pessoas, 14 apresentavam teste de Mantoux positivo. Destas, 5 apresentavam tuberculose pulmonar, diagnosticada através de exames clínicos e radiológicos. Os doentes eram representados pela mãe, que referia sintomas há 2 meses e 4 crianças com história de pneumonia de repetição há aproximadamente um ano. Foi realizada, na mãe, a pesquisa de micobactéria em escarro, resultando em baciloscopia positiva.

A familia possuía uma cadela e 2 gatos, todos aparentemente sadios e que conviviam com a família desde seu nascimento (exceto um dos gatos). $\mathrm{Na}$ cadela, foram realizados exames clínico, hemograma, análise de urina, broncoscopia para realização de baciloscopia (Ziehl-Neelsen), radiografia torácica e teste de Mantoux na face interna da coxa (Greene ${ }^{4}, 1984$ ). A radiografia torácica demonstrou múltiplas infiltrações broncopneumônicas, e a baciloscopia apresentou Bacilos Álcool Ácidor Resistentes (BAAR), sendo os demais examc negativos.

À realizaçīo da necrópsia não foram observadas alterações macroscópicas, sendo encaminhado material para realização do histopatológico. Ao exame microscópico dos cortes corados pela He- 
matoxilina-Eosina de pulmão, linfonodos mediatínicas, rins e intestino delgado observou-se predominância de infiltrado inflamatório mononuclear. Observou-se ainda que os macrófagos presentes na região medular tinham o citoplasma repleto de material fagocitado.

Nos cortes histológicos dos linfonodos mediastínicos, corados pelo método de Ziehl-Neelsen, foram observados no citoplasma dos macrófagos a presença de material particulado de coloração eosinofílica (compatível com micobactérias).

A baciloscopia positiva na cadela e seu comportamento amigável caracterizam este animal como uma fonte de infecção em potencial. A ausência de sitomatologia clínica e alterações macroscópicas, indicam a impossibilidade diagnóstica neste animal, quando da inexistência de suspeita de tuberculose.

Histologicamente, os carnívoros diferem das outras espécies pois raramente apresentam células gigantes (Jubb e col. ${ }^{5}, 1989$ ). A ausência de alterações histopatológicas características, associadas à presença de BAAR na coloração de Zieh1Neelsen, definem o diagnóstico de tuberculose na cadela, porém sugerem que a mesma se encontrava em fase inicial de desenvolvimento.

O diagnóstico de tuberculose nesse animal não seria realizado se não houvesse a suspeita baseada em dados epidemiológicos. A permanência do animal no ambiente, possibilitaria exposições constantes e prolongadas de pessoas ou animais ao agente, favorecendo novas infecções.

Não se sabe exatamente o perigo que o cão tuberculoso representa para o homem (Foster e col. $^{3}, 1986$ ), sendo poucos casos em que se pôde comprovar a transmissão do cão ao homem, porém é inquestionável que o cão tuberculoso (e mesmo o animal aparentemente sadio que coabita com pacientes tuberculosos), representa um risco em potencial, devendo ser recomendado seu sacrifício (Acha e Szyfres ${ }^{1}, 1986$ ).

A queda do nível de vida e condições socieconômicas populacionais, bem como a presença da AIDS fez com que a tuberculose que se encontrava em nível decrescente, retomasse seu crescimento de forma preocupante. Além das medidas indicadas pela Organização Mundial de Saúde para o controle da tuberculose (OPAS $\left.{ }^{7}, 1987\right)$, talvez fosse importante se questionar a importância do rastreamento epidemiológico direcionado, não somente aos contactantes humanos mas, também, aos animais da família. Esta conduta poderia colaborar no controle da tuberculose.

O rastreamento poderia ser uma ação conjunta entre médicos sanitaristas e médicos veterinários que atuem em nível de saúde pública. Essa atuação possibilitaria o controle da tuberculose através da deteç̧ão de casos humanos e seus contactantes e impediria a permanência de animais positivos que representam uma fonte de infecção em potencial não somente para a família, mas, também, para outros que com eles convivam.

MEGID, J. et al. [Canine tuberculosis and its importance in public health]. Rev. Saúde Pública, 28: 309-10, 1994. The present paper describes tuberculosis in a family whose dog also presented the disease. The importance of animal epidemiological investigation in cases of tuberculosis in man is discussed.

Keywords: Tuberculosis, epidemiology. Dog diseases. Epidemiologic surveillance.

\section{Referências Bibliográficas}

1. ACHA., P.N. \& SZYFRES, B. Zoonoses y enfermidades transmisibles comunes al hombre y a los animales. Washington, D.C., Organización Panamericana de la Salud, 1989. (OPAS - Publicación Científica, 503).

2. BENENSON, A.S. El control de las enfermedades transmisibles en el hombre. Washington, D.C., Organización Panamericana de la Salud, 1992. (OPAS - Publicación Científica, 538).

3. FOSTER, S.E. et al. Cutaneous lesion caused by Mycobacterium tuberculosis in a dog. JAMA, 188:1188-90, 1986.

4. GREENE, E.C. Infectious deseases of the dog and cat. Philadelphia, W.B. Saunders, Co., 1990.

5. JUBB, K.N.F. et al. Pathology of domestic animals. 3ed, London, Academic Press, 1989. v.2.

6. MANDELL, G.L.; DOUGLAS JR., R.G.; BENNETT, J.E Principles and practice of infections diseases. 2nd ed New York, John Wiley, 1985.

7. ORGANIZACIÓN PANAMERICANA DE LA SALUD. Control de las tuberculosis: manual sobre metodos y procedimientos para los programas integrados. Washington, D.C. (OPAS - Publicación Científica, 498).

8. STEELE, J.H. Handbook series in zoonosis. Boca Raton, CRC Press, 1980. Sect A, v.2.

\footnotetext{
Recebido para publicação em 24.3.1994 Reapresentado em 26.6.1994 Aprovado para publicaçāo em 28.7.1994
} 